\title{
Nonlinear Second-Order Model and Equilibrium Point Characteristic Analysis of DC Traction Power Supply System
}

\author{
Y. H. Li, ${ }^{1}$ X. J. Tian, ${ }^{1}$ and X. Q. Li $^{2}$ \\ ${ }^{1}$ School of Automation Science and Electrical Engineering, Beihang University, Beijing 100191, China \\ ${ }^{2}$ College of Information Engineering, Beijing Institute of Petrochemical Technology, Beijing 102617, China \\ Correspondence should be addressed to X. Q. Li; lixiaqing@bipt.edu.cn
}

Received 21 April 2013; Accepted 9 June 2013

Academic Editors: E. Kita and H.-T. Yau

Copyright (c) 2013 Y. H. Li et al. This is an open access article distributed under the Creative Commons Attribution License, which permits unrestricted use, distribution, and reproduction in any medium, provided the original work is properly cited.

\begin{abstract}
According to the different features of the DC traction network transient current in the Metro, the electromagnetic transient process of traction power supply system that should be divided into the two forms of short-circuit fault and the low-frequency oscillation was proposed. While traction network short-circuit fault happens, the system model is a weakly nonlinear first-order differential equation, which feeder current is increasing exponentially and eventually stabilized. While the load current becomes low-frequency oscillation current, the system model is a nonlinear second-order differential equation. After linear processing in unique equilibrium point neighborhood, the state space equation of linear system is built, and the structural reason of lowfrequency oscillation is revealed by eigenvalue analysis method. The simulation result shows that the simulation current waveforms are consistent with the recorded current waveforms and the division of transient process is reasonable.
\end{abstract}

\section{Introduction}

Metro becomes the favor of big cities in the world because of its transport features of rapid, larger capacity, three dimensions, and environment protection effect of green, pollutionfree [1]. Because Metro vehicle adopts electric traction, their safe operation state depends on stability of the DC traction power supply system (TPSS) and its fault protection measures. Traditionally, the main factor which influences Metro operation safety is the traction network short-circuit fault of high incidence and heavy harmfulness. However, with the continuous increase of transport capacity and the extensive application of regenerative braking technology, the low-frequency oscillation current of high incidence appears in traction network, which has the characteristic of faster start up and short duration, and is not characterized as fault. However, as the similarity of divergent oscillation current and remote short-circuit fault current in the amplitude and slope feature, the protection device often regards oscillation current as fault current and causes the protection system malfunction. Both determination of traction network fault type and reveal of oscillation generation mechanism rely on the analysis of electromagnetic transient process of TPSS; thus it is very significance to establish accurately system model and study its stability for Metro operation safety.

While the traction network short-circuit fault happens, the electromagnetic transient model of TPSS is presently the zero-state response of first-order $R L$ series circuit [2], whose corresponding main protection algorithm is the combination algorithm of $d i / d t-\Delta i$ (current rate-current increment) $[3,4]$, thereby the feeder current increases by index law and reaches eventually a stable status during the traction network short-circuit fault. Against the fact that there exist oscillation phenomenon in the transient current of traction network, the transient model considering AC side of power supply effect to short-circuit current waveform is presented in [5], and the simulation waveform with "overshoot" phenomenon and the important conclusion of positive correlation between overshoot degree and fault distance are got. The transient physical model of TPSS that is a second-order $R L$ hybrid circuit is presented in [6], the short-circuit current is provided from many nearby substations, and the same conclusion is concluded. However, it can be learned from actual recorded current waveform of Beijing Metro that the oscillation phenomenon does not appear in feeder current during short-circuit fault of traction network, while the 


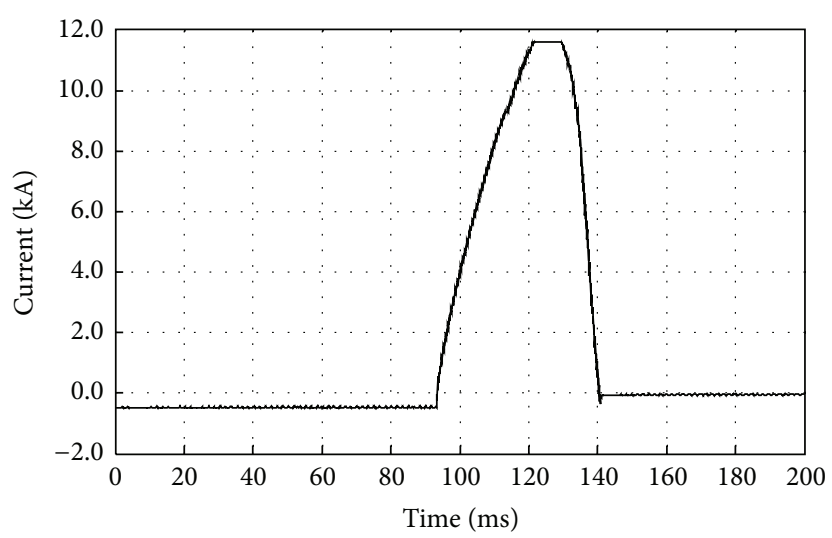

(a) Short-circuit fault current

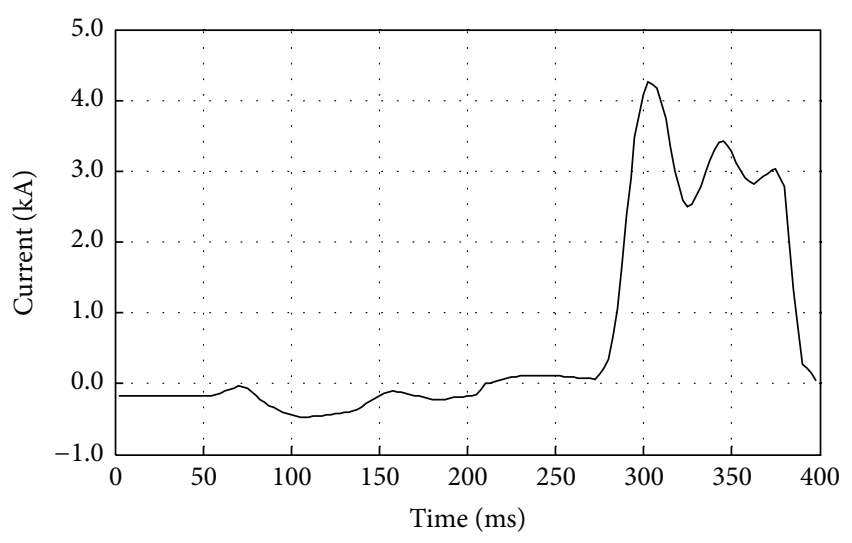

(b) Low-frequency oscillation current

FIGURE 1: Transient current waveform of traction network.

obvious low-frequency oscillation process appears in normal operation stages, so the electromagnetic transient process of TPSS should be divide into the two forms of short circuit fault and the low-frequency oscillation.

It can be learned from the waveform analysis of shortcircuit and oscillation current that the electrical drive structure of vehicle and operation status have great influence to oscillation process, so the transient model of TPSS should take vehicle factor into consideration. Firstly, the transient model of TPSS is established during the traction network short-circuit, and the fault type is determined by the feeder current analysis of transition process and change feature. Secondly, the nonlinear second-order dynamic system model considering vehicle factor and the corresponding linear system model in balance-point neighborhood are established, and the structural reasons of low-frequency oscillation is concluded by analysis of the state space matrix of linear system.

\section{Transient Current and Waveform Feature of Traction Network}

The function of DC TPSS is to change three-phase AC voltage into DC $750 \mathrm{~V}$ (or DC $1500 \mathrm{~V}$ ) voltage by step-down and rectifier and then provide power to vehicle by the overhead contact line (or the contact rail). The TPSS is mainly composed of DC traction substation, feeder, DC traction network (contact line and travel rail), and return line, and its structure features are bilateral power supply and shorter transmission line.

At present, the two types of transient current waveform of traction network short-circuit fault and system lowfrequency oscillation are recorded in line 1 of Beijing Metro, as shown in Figure 1. In Figure 1(a), the protection started at $100 \mathrm{~ms}$, and the fault is cut off before it reaches steady state, while in Figure 1(b), the protection started at $300 \mathrm{~ms}$, and power supply is cut off before it reaches peak.

It can be seen from Figure 1(a) that the short-circuit fault current waveform has the following features: (1) the current pulsation amplitude is very small before short-circuit fault, while the current rises exponentially and reaches peak (or saturation value) in shorter time after fault; (2) the current has a certain initial value, which indicates that traction network is firstly in transmission condition and then happens to shortcircuit fault, and its change rule does follow the zero-state response of first-order $R L$ serials circuit. These two features have been confirmed by the recorded short-circuit fault cases of traction network of Beijing Metro in the last two years.

Figure 1(b) shows that the oscillation current has the following features: (1) the startup of oscillation is quick, the duration is generally less than $1 \mathrm{~s}$, and the oscillation period is about $100 \mathrm{~ms}$; (2) the start-up point at the negative current indicates that vehicle is in a regenerative braking state; (3) the amplitude of oscillation current is small, even smaller than the traction load current.

It can be concluded by the previous analysis that these two types of transient current have essential difference in waveform morphology and generation mechanism. Therefore, the modeling and analysis of TPSS will be carried out in accordance with two forms of traction network short-circuit fault and system low-frequency oscillation.

\section{Modeling and Analysis of TPSS during the Traction Network Fault}

3.1. Physical Model of Traction Substation. Generally, it is suitable that the equivalent modeling of traction substation adopts the theorem of L.C. Thevenin in study and analysis of TPSS electromagnetic transient process. The main electrical equipment of traction substation is 24-pluse rectifier unit (combination of traction transformer and rectifier), and the work feature of rectifier unit is that its external characteristic (function relation between DC output voltage and load current) is a weakly nonlinear relationship. What is more, the AC side equivalent inductance makes little effect on operation of TPSS because of large leakage reactance of rectifier transformer. Therefore, the equivalent physical model of traction substation is the series circuit of ideal voltage source $E$ and internal resistance $r$, as shown in Figure 2. 


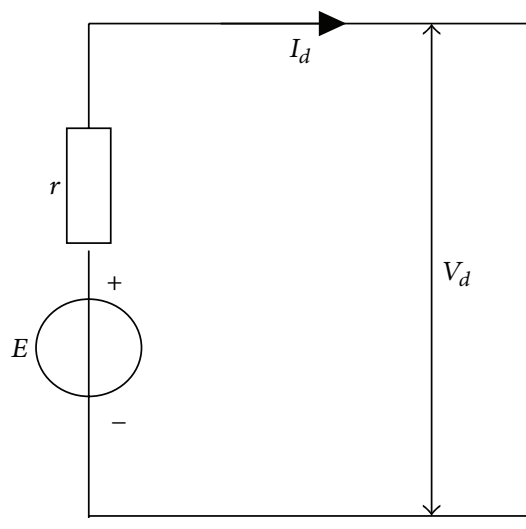

FIGURE 2: Equivalent physical model of traction substation.

Obviously, the absolute value of characteristic curve slope is the internal resistance $r$, and the intercept of $y$ axis is the voltage value of ideal voltage source $E$, thereby the output equation of substation is

$$
V_{d}=E-I_{d} r
$$

3.2. System Modeling and Qualitative Analysis. The transmission lines of TPSS are uniform structure, their total length is generally less than $3 \mathrm{~km}$, and voltage is low; thereby the equivalent resistance model of short-circuit line can be used in modeling of transmission line. Thus, the electromagnetic transient physical model of TPSS during traction network short-circuit fault can be got according to the model of substation and transmission line, as shown in Figure 3.

It can be learned from the circuit structure that the electromagnetic transient physical model of TPSS is a weakly nonlinear first-order $R L$ series circuit, and the two series circuits are independent. In Figure $3, d$ is the distance between substation $\mathrm{A}$ and substation $\mathrm{B}, d_{x}$ is the distance between short-circuit point and substation $\mathrm{A}, u_{f}$ is the arc voltage (only relevant to the arc length), voltage value of ideal voltage source is $E_{0}$, and $i_{1}$ and $i_{2}$ are, respectively, feeder currents provided by substations $\mathrm{A}$ and $\mathrm{B}$. In addition, if we assumed that the resistance $\rho_{0}$ and inductance $\xi_{0}$ of unit length for contact line and the resistance $\rho_{1}$ and inductance $\xi_{1}$ of unit length for travel rail are constant value, while the current changes, then the contact line impedance $\left(Z_{11}, Z_{12}\right)$ and travel rail impedance $\left(Z_{21}, Z_{22}\right)$ are proportional to distance of power supply.

According to the mesh current method and round direction shown in Figure 3, the first-order differential equations of feeder current based on small signal analysis method are

$$
\begin{gathered}
\left(r_{1}+\rho d_{x}\right) \Delta i_{1}+\xi x \frac{d \Delta i_{1}}{d t}=\Delta E_{0}-\Delta u_{f}, \\
{\left[r_{2}+\rho\left(d-d_{x}\right)\right] \Delta i_{2}+\xi\left(d-d_{x}\right) \frac{d \Delta i_{2}}{d t}=\Delta E_{0}-\Delta u_{f},}
\end{gathered}
$$

where $\rho=\rho_{0}+\rho_{1}$ and $\xi=\xi_{0}+\xi_{1}$.

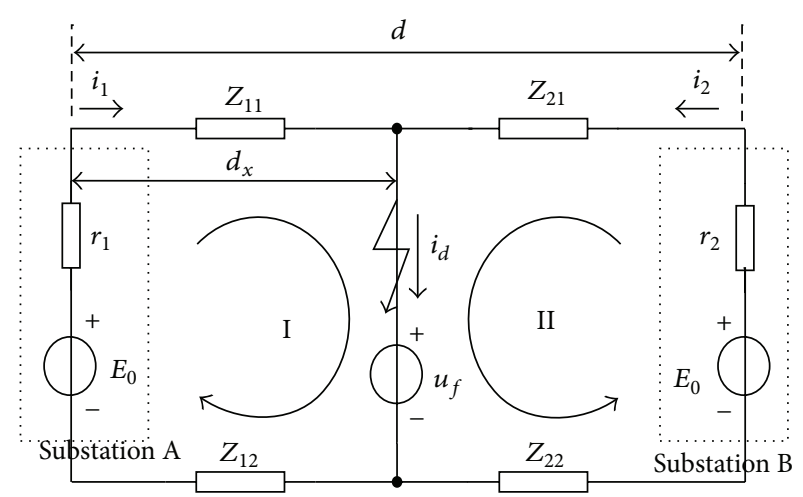

FIgURE 3: Transient physical model of TPSS during traction network fault.

The time-domain solution of (2) is

$$
\begin{aligned}
\Delta i_{1} & =\frac{\Delta E_{0}-\Delta u_{f}}{r_{1}+\rho d_{x}}\left(1-e^{-\left(\left(r_{1}+\rho d_{x}\right) / \xi d_{x}\right) \times t}\right) \\
& \triangleq i_{p 1}-i_{m 1}, \\
\Delta i_{2}= & \frac{\Delta E_{0}-\Delta u_{f}}{r_{2}+\rho\left(d-d_{x}\right)} \\
& \times\left(1-e^{-\left(\left(r_{2}+\rho\left(d-d_{x}\right)\right) / \xi\left(d-d_{x}\right)\right) \times t}\right) \\
\triangleq & i_{p 2}-i_{m 2} .
\end{aligned}
$$

It is shown in formula (3) that the small signal of feeder currents $\Delta i_{1}$ and $\Delta i_{2}$ contains two components of steady-state and transient if the traction network short-circuit fault occurs in $t=0$. That is, the feeder current $\Delta i_{1}$ contains steadystate component $i_{p 1}$ and transient components $i_{m 1}$, and the feeder current $\Delta i_{2}$ contains steady-state component $i_{p 2}$ and transient component $i_{m 2}$. As time goes on, the transient component $i_{m 1}$ and $i_{m 2}$ will attenuate in accordance with the law of exponential function, while the feeder current increases exponentially and eventually stabilizes to a steadystate current.

Through the real-time simulation of transient model of TPSS carried in the digital simulation platform of RT-Lab, the time-domain transition process of feeder current is obtained, and the simulation result is shown in Figure 4.

It can be seen from the simulation results that the simulation waveform is consistent with the recorded fault current waveform in change process; fault steady-state current value and first-order $R L$ circuit response characteristics are decided by the value of substation internal resistance and traction network resistance at fault moment; and feeder current value is positive correlation to fault distance; the change rule of feeder current follows the zero-state response of first-order $R L$ series circuit.

\section{Modeling and Analysis of TPSS during Low- Frequency Oscillation}

Currently, the AC speed regulation train with VVVF function and EMU (electrical multiple units) is widely used in Beijing 


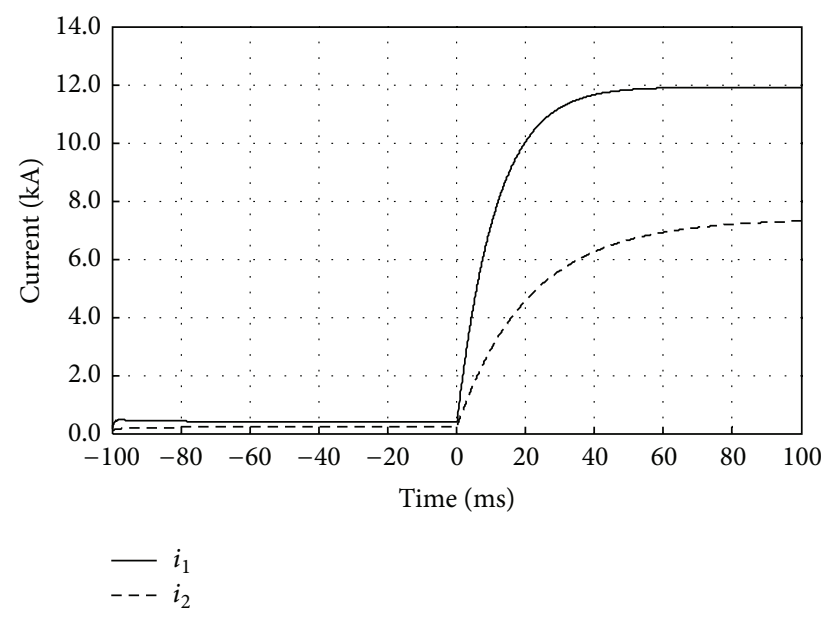

FIGURE 4: Simulation waveform of feeder currents during traction network short circuit.

Metro, each train has usually six marshalling (4 EMUs +2 trailers), and each EMU is equipped with two sets of AC speed regulation device with a filter capacitor of $12 \mathrm{mF}$ and a filter inductance of $6 \mathrm{mH}$. In addition, all inverters and AC motors of vehicle can be equivalent to the series circuit of nonlinear negative resistance and DC voltage source.

4.1. Physical Model of Low-Frequency Oscillation. The aim of regenerative braking of Metro is to achieve the effect of energy saving by converting the part of vehicle kinetic energy into electric power and feedback it to DC traction network. Therefore, the operating status of regenerative braking is that the traction motors are in running condition and the voltage of traction network is higher than the voltage of rectifier unit. Considering that the low-frequency oscillation of TPSS occurs in regenerative braking condition, obviously the vehicle is an important part of TPSS at this time. Thus, the electromagnetic transient physical model of TPSS during the low-frequency oscillation is established by the model of electric drive, substation, and transmission, as shown in Figure 5(a).

It can be seen from Figure 5(a) that the transient network physical model of TPSS during low-frequency oscillation is a nonlinear second-order $R L C$ hybrid series circuit network and the DC voltage source of vehicle which contains a certain low-frequency component can be regarded as the system disturbance source. In the vehicle model part, $C_{p}$ is the filter capacitor, $L_{p}$ is the filter inductance, and $r_{m}$ is the equivalent nonlinear resistor of electric drive (traction converters and motors).

To simplify the calculation and analysis, the equivalent transformation of the transient model is carried, and the transformation results are shown in Figure 5(b). Thus, according to the contrast analysis of circuit structure, the quantitative relation of main circuit parameters is

$$
\begin{aligned}
& i=i_{1}+i_{2}, \\
& r=\frac{r_{1} r_{2}}{r_{1}+r_{2}},
\end{aligned}
$$

$$
\begin{gathered}
R_{1}=\frac{\rho d_{x}\left(d-d_{x}\right)}{d}, \\
L_{1}=\frac{\xi d_{x}\left(d-d_{x}\right)}{d}+L_{p}, \\
\rho=\rho_{0}+\rho_{1}, \\
\xi=\xi_{0}+\xi_{1} .
\end{gathered}
$$

4.2. Determination of the Equilibrium Point. It can be concluded from Figure 5(b) that the system physical model is a nonlinear second-order $R L C$ hybrid circuit after equivalent transformation. Therefore, the mathematical model of feeder current is a second-order nonlinear differential equation, which can be described by two first-order differential equations as

$$
\begin{gathered}
E_{0}=\left(R_{1}+r\right) i+L_{1} \frac{d i}{d t}+u_{c}, \\
u_{c}=r_{m} i+r_{m} C_{p} \frac{d u_{c}}{d t}+E_{m} .
\end{gathered}
$$

Because it is difficult to discuss the phase diagram on the entire phase plane for formula (5), the qualitative information is usually obtained by the discussion of local properties in the equilibrium point neighborhood, and the solution properties in the equilibrium point neighborhood can be studied by linearization method.

While vehicle is in the regenerative braking status, the operation condition of its electric drive system is very complex. If we assumed that the output power is constant and ignore the energy loss of electrical equipment, the voltagecurrent characteristic of nonlinear resistance $r_{m}$ is a function relationship of inverse proportion. Therefore, the external characteristics of converter can be described as

$$
\begin{gathered}
u_{m} i_{m}=-P=-k, \\
r_{m}=-\frac{u_{c}^{2}}{P},
\end{gathered}
$$

where $u_{m}$ and $i_{m}$ are, respectively, the output voltage and the output current of converter, $k$ is a positive real constant, and $P$ is the output power of inverter.

In formula (5), the equilibrium points meet conditions of $d u_{c} / d t=0$ and $d i / d t=0$, so the second-order nonlinear differential equations of the feeder current can be simplified as

$$
\left(R_{1}+r+r_{m}\right) i=E_{0}-E_{m} .
$$

Formula (7) is a monotonic function, and the voltagecurrent characteristic of nonlinear resistance $r_{m}$ is still a monotonic function after linear transformation; thereby these two monotonic functions have only one intersection point which indicates that the circuit working point is the only equilibrium point. Therefore, after the inductances are replaced with short circuit and the capacitors are replaced 


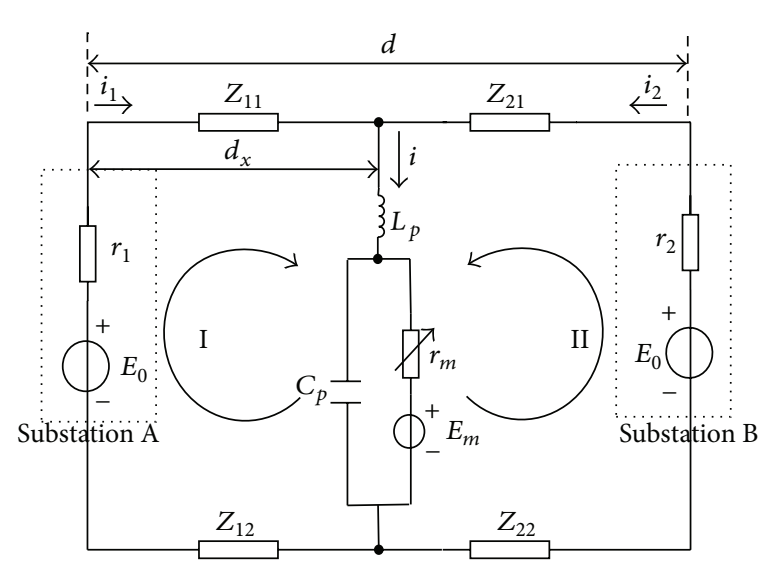

(a) Transient model

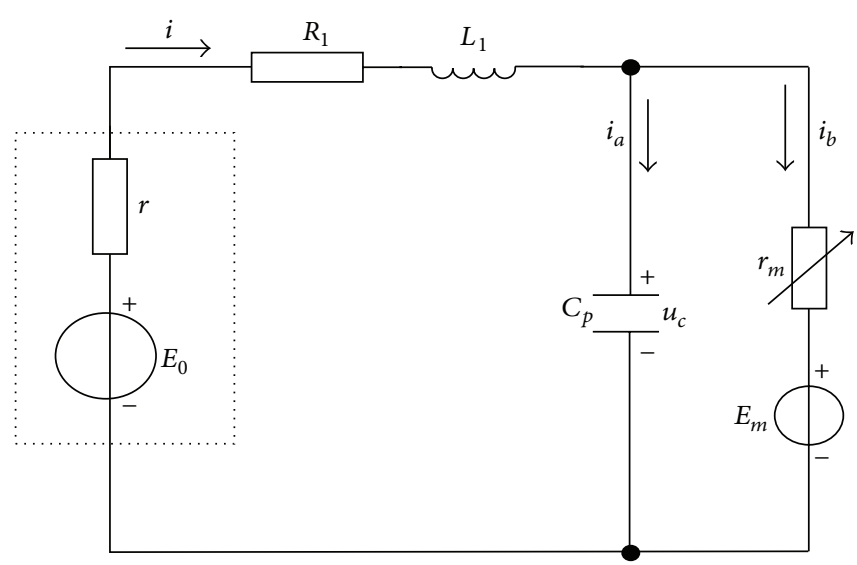

(b) Equivalent transient model

FIGURE 5: Transient physical model of TPSS during low-frequency oscillation.

with open circuit in Figure 5, the equilibrium working point $M\left(x_{e}, y_{e}\right)$ can be obtained using KVL; that is,

$$
M\left(x_{e}, y_{e}\right)=\left(\frac{E_{0}-E_{m}}{R_{1}+r-r_{m}}, \frac{\left(R_{1}+r\right) E_{m}-r_{m} E_{0}}{R_{1}+r-r_{m}}\right) .
$$

4.3. Equilibrium Point Properties of the General SecondOrder Dynamic Circuit. Generally, the equation of nonlinear second-order dynamic circuit can be described by formula (9) as follows

$$
\begin{aligned}
& \frac{d x}{d t}=X(x, y), \\
& \frac{d y}{d t}=Y(x, y) .
\end{aligned}
$$

So, formula (9) in the equilibrium point neighborhood can always be transformed into

$$
\left[\begin{array}{l}
\frac{d x}{d t} \\
\frac{d y}{d t}
\end{array}\right]=\left[\begin{array}{ll}
a & b \\
c & d
\end{array}\right]\left[\begin{array}{l}
x \\
y
\end{array}\right]+\left[\begin{array}{l}
f(x, y) \\
g(x, y)
\end{array}\right] .
$$

In formula (10), $f(x, y)$ and $g(x, y)$ are the functions that is composed of the quadratic term and the more order item, and

$$
\begin{array}{ll}
a=\left.\frac{\partial X}{\partial x}\right|_{x=y=0}, & b=\left.\frac{\partial X}{\partial y}\right|_{x=y=0}, \\
c=\left.\frac{\partial Y}{\partial x}\right|_{x=y=0}, & d=\left.\frac{\partial Y}{\partial y}\right|_{x=y=0} .
\end{array}
$$

Without considering the higher-order terms, then

$$
\left[\begin{array}{l}
\frac{d \zeta_{1}}{d t} \\
\frac{d \zeta_{2}}{d t}
\end{array}\right]=\left[\begin{array}{ll}
a & b \\
c & d
\end{array}\right]\left[\begin{array}{l}
\zeta_{1} \\
\zeta_{2}
\end{array}\right]=\mathbf{A}\left[\begin{array}{l}
\zeta_{1} \\
\zeta_{2}
\end{array}\right]
$$

Obviously, the formula (12) is the linear equation of formula (9) in the neighborhood of equilibrium point, and $\zeta_{1}=$ $0, \zeta_{2}=0$ are the equilibrium points of formula (12). If the matrix $\mathbf{A}$ does not exist eigenvalues with zero-real part, the equilibrium point of non linear equation is called the hyperbolic equilibrium point. The trajectory shape in the hyperbolic equilibrium point has the same characteristics with the trajectory shape of linear equations (12) in the equilibrium point. Therefore, when the equilibrium point of the linear system is, respectively, a saddle point, node, and focus, the equilibrium point of corresponding nonlinear system is also, respectively, saddle point, node and focus, and the trajectory of nonlinear system and linear system are tangent at the equilibrium point.

4.4. Properties of Equilibrium Point during System Low-Frequency Oscillation. According to the previous linearization method of second-order dynamic circuit and designating the traction current $i$ and the filter capacitor voltage $u_{c}$ as state variables, the state space equation of the formula (5) in the neighborhood of equilibrium point $M\left(x_{e}, y_{e}\right)$ is

$$
\begin{aligned}
{\left[\begin{array}{c}
\frac{d i}{d t} \\
\frac{d u_{c}}{d x}
\end{array}\right]=} & {\left[\begin{array}{cc}
-\frac{R_{1}+r}{L_{1}} & -\frac{1}{L_{1}} \\
\frac{1}{C_{p}} & -\frac{1}{r_{m} C_{p}}
\end{array}\right]\left[\begin{array}{c}
i \\
u_{c}
\end{array}\right] } \\
& +\left[\begin{array}{cc}
\frac{1}{L_{1}} & 0 \\
0 & \frac{1}{r_{m} C_{p}}
\end{array}\right]\left[\begin{array}{c}
E_{0} \\
E_{m}
\end{array}\right] .
\end{aligned}
$$

The compact form of (13) is

$$
\left[\begin{array}{c}
i \\
\dot{u_{c}}
\end{array}\right]=\mathbf{A}\left[\begin{array}{c}
i \\
u_{c}
\end{array}\right]+\mathbf{B}\left[\begin{array}{c}
E_{0} \\
E_{m}
\end{array}\right]
$$

In formula (14), $\mathbf{A}$ is the state matrix, and $\mathbf{B}$ is the input matrix. 
TABLE 1: Relationship between eigenvalue and type of equilibrium point.

\begin{tabular}{lc}
\hline Eigenvalues & Type of equilibrium point \\
\hline$p^{2}-4 q>0$ and $p>0$ & Stable node \\
$p^{2}-4 q>0$ and $p<0$ & Unstable node \\
$p^{2}-4 q>0$ and $q<0$ & Saddle \\
$p^{2}-4 q<0$ and $p<0$ & Unstable focus \\
$p^{2}-4 q<0$ and $p>0$ & Stable focus \\
$p=0$ & Uncertain \\
\hline
\end{tabular}

If we assume $\left(i_{0}, u_{c 0}\right)$ to be the initial value of formula (14) of $t=0$, its solution can be expressed as

$$
\left[\begin{array}{c}
i \\
u_{c}
\end{array}\right]=\left[\begin{array}{c}
i_{0} \\
u_{c 0}
\end{array}\right] e^{A t} \triangleq \mathbf{u} e^{A t} .
$$

The linear system has only one equilibrium point $M\left(x_{e}\right.$, $\left.y_{e}\right)$, and the property of the equilibrium point is decided by the eigenvalue of matrix $\mathbf{A}$.

The characteristic equation is

$$
\begin{aligned}
\operatorname{det}(\lambda \mathbf{I}-\mathbf{A})= & \lambda^{2}+\left(\frac{r+R_{1}}{L_{1}}+\frac{1}{r_{m} C_{p}}\right) \lambda \\
& +\frac{\left(r+R_{1}\right)+r_{m}}{r_{m} L_{1} C_{p}}=0 .
\end{aligned}
$$

The new variables $p$ and $q$ are defined as

$$
\begin{gathered}
p=\frac{r+R_{1}}{L_{1}}+\frac{1}{r_{m} C_{p}}, \\
q=\frac{\left(r+R_{1}\right)+r_{m}}{r_{m} L_{1} C_{p}} .
\end{gathered}
$$

Thus, the eigenvalues of formula (16) are

$$
\lambda_{1}, \lambda_{2}=\frac{-p \pm \sqrt{p^{2}-4 q}}{2}
$$

When the parameters of matrix A change, the eigenvalues $\lambda_{1}, \lambda_{2}$ will have lots of combination forms, and the results are shown in Table 1 after being discussed.

\subsection{Analysis and Simulation of Divergent Low-Frequency} Oscillation. Considering the malfunction of relay protect caused by divergent low-frequency oscillation, it is necessary to carry detailed analysis of divergent low-frequency oscillation.

When the divergent low-frequency oscillation occurs, the system equilibrium point is an unstable focus, and the eigenvalues $\lambda_{1}, \lambda_{2}$ are a pair of conjugate roots of positive real part, that is, $\lambda_{1}, \lambda_{2}=\sigma \pm j \omega$, so the conditions of divergent oscillation are

$$
\begin{gathered}
-r_{m}>\frac{L_{1}}{C_{p}\left(R_{1}+r\right)}, \\
{\left[r_{m} C_{p}\left(R_{1}+r\right)+L_{1}\right]^{2}<4 r_{m} L_{1} C_{p}\left[\left(r+R_{1}\right)+r_{m}\right] .}
\end{gathered}
$$

Many electrical parameters are involved in formula (19), and most of them are related to distance of power supply, so the results are difficult to obtain by direct calculation. Now enumeration method is used to verify the structural conditions of divergent oscillation.

The output power range of Metro vehicles converter is $0 \sim 2.4 \mathrm{MW}$, the output voltage is $825 \mathrm{~V}$, and then the change range of resistance $r_{m}$ is

$$
\left|r_{m}\right|=\frac{u_{c}^{2}}{P} \geq \frac{825^{2}}{2.4 \times 10^{6}}=0.2836(\Omega)
$$

In Figure 5, the filter inductor $L_{p}$ is $1.5 \mathrm{mH}$, and the filter capacitor $C_{p}$ is $48 \mathrm{mF}$ (the four sets of electrical drive units are parallel). The loop electrical parameters of unit length $\rho_{0}, \xi_{0}, \rho_{1}$, and $\xi_{1}$ are, respectively, $0.019 \Omega / \mathrm{km}$, $1.139 \mathrm{mH} / \mathrm{km}, 0.016 \Omega / \mathrm{km}$, and $0.328 \mathrm{mH} / \mathrm{km}$ if the actual average of resistance and inductance is adopted. Suppose that the power supply distance between two substations $(d)$ is $2 \mathrm{~km}$, the internal resistance of substation $r$ is $0.04 \Omega$, and fault distance $d_{x}$ is $0.5 \mathrm{~km}$ in representative instance, and substitute these electrical parameters into formula (4), then

$$
\begin{aligned}
& R_{1}=0.01313 \Omega, \\
& L_{1}=2.0501 \mathrm{mH} .
\end{aligned}
$$

Then, the parameters $R_{1}, L_{1}, r, L_{p}$, and $C_{p}$ are substituted into formula (19), and the result is

$$
\left|r_{m}\right|>0.8039 \Omega
$$

Therefore, while $\left|r_{m}\right|>0.8039 \Omega$, the system configuration is unstable.

Frequency $f$ and the damping ratio $\varsigma$ (this case is negative and which show diverging effect) are the two important indexes in describing oscillatory waveform morphology, so the relationship between indexes and electrical parameters can be expressed as

$$
\begin{gathered}
f=2 \pi \omega, \\
\varsigma=\frac{-\sigma}{\sqrt{\sigma^{2}+\omega^{2}}}, \\
\sigma=\frac{1}{2}\left(\frac{r+R_{1}}{L_{1}}+\frac{1}{r_{m} C_{p}}\right), \\
\omega^{2}=\frac{\left(r+R_{1}\right)-r_{m}}{r_{m} L_{1} C_{p}} .
\end{gathered}
$$

Generally, there exists condition of $\left|r_{m}\right| \gg\left(r+R_{1}\right)$ in formula (23), so

$$
f \approx \frac{2 \pi}{\sqrt{L_{1} C_{p}}} .
$$

Now, in order to clarify the feature of system divergent oscillation, the frequency $f$ and the damping ratio $\sigma$ are calculated by an actual example. Assuming that the actual 


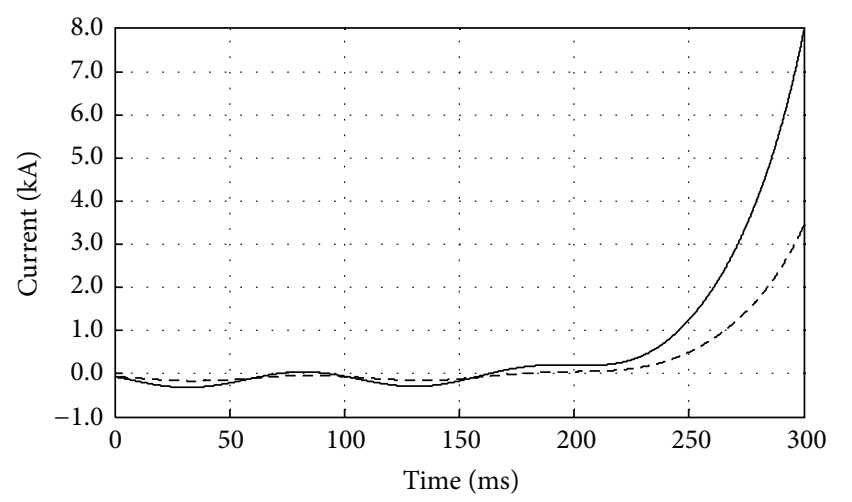

$-i_{1}$
$--i_{2}$

FIGURE 6: Simulation waveform of low-frequency oscillation.

output power of the converter is $80 \%$ of the maximum power and the output voltage is $825 \mathrm{~V}$, then

$$
\left|r_{m}\right|=\frac{u_{c}^{2}}{P}=\frac{825^{2}}{2.4 \times 10^{6} \times 80 \%}=3.545(\Omega) .
$$

Substitute $r_{m}=-3.545(\Omega)$ and other electrical parameters $\left(R_{1}, L_{1}, L_{p}, r\right.$ and $\left.C_{p}\right)$ into formula (23), and the result is

$$
\begin{aligned}
& f=12.23 \mathrm{~Hz}, \\
& \xi=-23.14 \% .
\end{aligned}
$$

From the calculation results, we can conclude the following: (1) the change of system oscillation frequency is small, and its calculation value is basically consistent with the actual oscillation frequency; (2) the damping ratio is relatively large in the neighborhood of equilibrium point, which indicates that the start up of system divergent oscillation is fast.

In addition, as can be learned from qualitative analysis of formula (16) and (19), the equivalent nonlinear negative resistance is the fundamental reason of system structure instability. Considering that in system model, the electrical parameters that can be easily adjusted are filter capacitor $C_{p}$ and filter inductor $L_{p}$, and the system structure stability can be improved by reducing $C_{p}$ and increasing $L_{p}$. However, it is required to reduce the cut off frequency of low-pass filter by increasing $C_{p} L_{p}$ in order to prevent vehicle disturbance into the TPSS, so the adjustable margin of structure parameters is very smaller.

Through the real-time simulation of low-frequency oscillation transient model of TPSS carried in the digital simulation platform of RT-Lab, the time-domain transition process of feeder current is obtained, as shown in Figure 6.

It can be seen from the simulation results that the simulation waveform is consistent with the recorded divergent oscillation current waveform in change process, the oscillation frequency is mainly determined by filter capacitor $C_{p}$ and filter induction $L_{p}$, and the positive damping ratio is mainly affected by the equivalent resistance $r_{m}$ of electric drive.

\section{Conclusion}

Currently, there exist two types of transient current in the DC traction network, namely, short-circuit fault current with increasing exponentially and low-frequency oscillating current with faster startup and short duration. Because the short circuit fault of traction network can make great harm to system, the action of short-circuit is characterized as a serious fault. The divergent low-frequency oscillation does not belong to short-circuit fault, but it will cause malfunction of relay protection because of the imperfect of electromagnetic transient model of TPSS. Therefore, the two types of transient current have essential difference in waveform feature and generation mechanism.

When the short-circuit fault of DC traction network occurs, the electromagnetic transient physical model of TPSS is a weakly nonlinear first-order $R L$ series circuit, and the mathematical model of feeder current is a weakly nonlinear first-order differential equations based on the small-signal analysis methods. It can be learned from analysis of the feeder current time-domain solution that the feeder current is composed of steady-state component and transient components, and the steady-state component is independent of time, while the transient component will decrease exponentially with time. Therefore, the feeder current will increase exponentially and eventually stabilize to a steady-state current, which indicates that the change of feeder current is a monotonically increasing process. In addition, it can be learned from simulation experiment that the feeder current value is positivly correlated with fault distance, so the short-circuit fault type can be judged by the value of feeder current.

It can be learned from waveform feature of transient current that the system low-frequency oscillation appears in vehicle regenerative braking state, and the structure of the system itself is a first-order $R L$ series circuit, hence the vehicle must be incorporated in the TPSS in transient modeling. The equivalent model of vehicle electric drive is a series circuit; of DC voltage source and non-linear negative resistance, so the electromagnetic transient physical model of TPSS with vehicles is a nonlinear second-order $R L C$ hybrid circuit, and the mathematical model of feeder current is a nonlinear second-order differential equations.

The transient model of TPSS with vehicle is a complex nonlinear second-order dynamic system, so it is a relatively simple method in discussing the stability of system structure that the linear process of model is carried in the neighborhood of equilibrium point. The operating point is the equilibrium point of the system; thus the transient model can be transformed into a linear system in the neighborhood of operating point. As can be learned by analysis of the state space matrix analysis of linear system, the equivalent resistance of electric drive is the main electrical parameters that affect system instability and positive damping process, while the system oscillation frequency depends mainly on filter capacitor and filter inductor. In addition the frequency is the essential attribute of system structure, and its change is small, so the relay protection algorithm of DC traction network based on the frequency characteristic can effectively distinguish oscillation current and fault current. 


\section{Acknowledgment}

This paper was supported by Scientific Research and Development Planning Projects "Study of Automation Systems Solutions and Technical Specifications in Traction Power Supply" in Ministry of Railways, China, under Grant 2007J022.

\section{References}

[1] X. Li and L. Zuo, "Energy spectrum and eigenvector of DC traction power supply short-circuit current," Transactions of China Electrotechnical Society, vol. 25, no. 11, pp. 164-168, 2010.

[2] J. C. Brown, J. Allan, and B. Mellitt, "Calculation of remote short circuit fault currents for DC railways," IEE Proceedings $B$, vol. 139, no. 4, pp. 289-294, 1992.

[3] B. Lang, "Research on feeder protection for DC traction power supply system," Journal of Beijing Jiaotong University, vol. 33, no. 5, pp. 65-68, 2009.

[4] G. F. Wang, Y. K. Sun, and K. H. Chen, "DDL protection in subway DC traction power supply system," Proceedings of the CSU-EPSA, vol. 19, no. 1, pp. 59-62, 2007.

[5] K. Kongwei, Q. Qinlijun, Y. Yangqixun, and D. Dingfuhua, "DC side short circuit transient simulation of DC traction power supply system," in Proceedings of the International Conference on Power System Technology (POWERCON '04), pp. 182-186, November 2004.

[6] C. L. Pires, S. I. Nabeta, and J. R. Cardoso, "Second-order model for remote and close-up short-circuit faults currents on DC traction supply," IET Power Electronics, vol. 1, no. 3, pp. 348-355, 2008. 


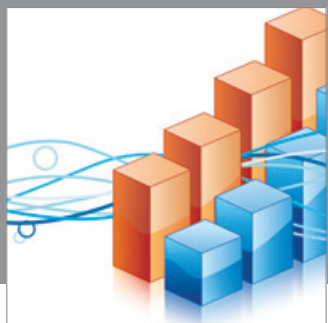

Advances in

Operations Research

mansans

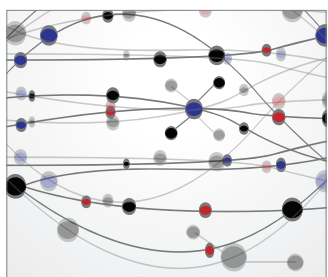

The Scientific World Journal
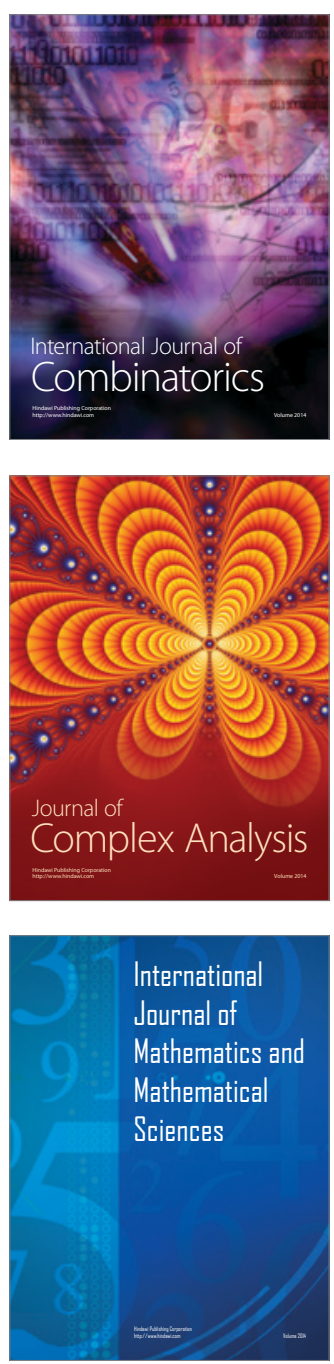
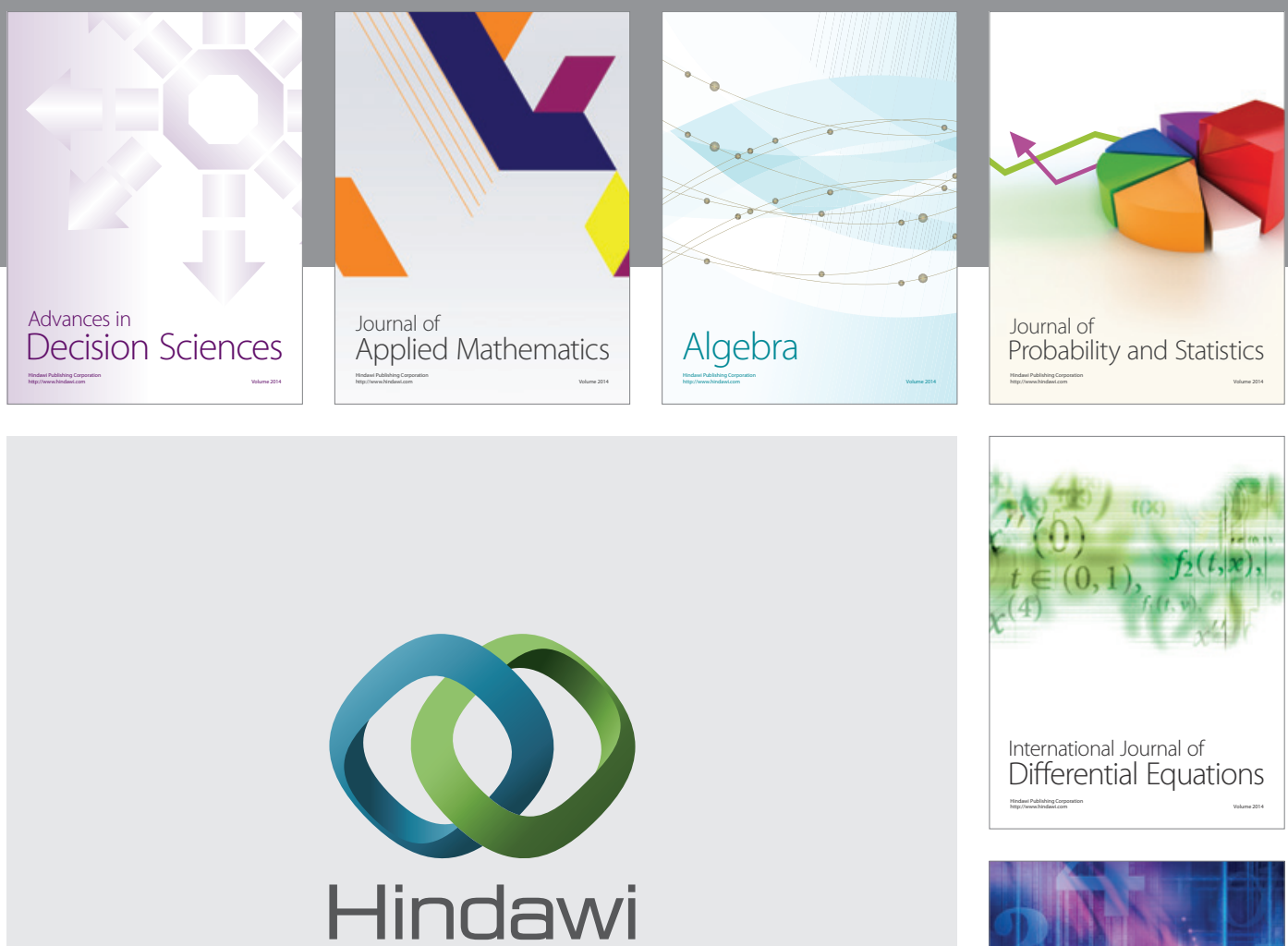

Submit your manuscripts at http://www.hindawi.com
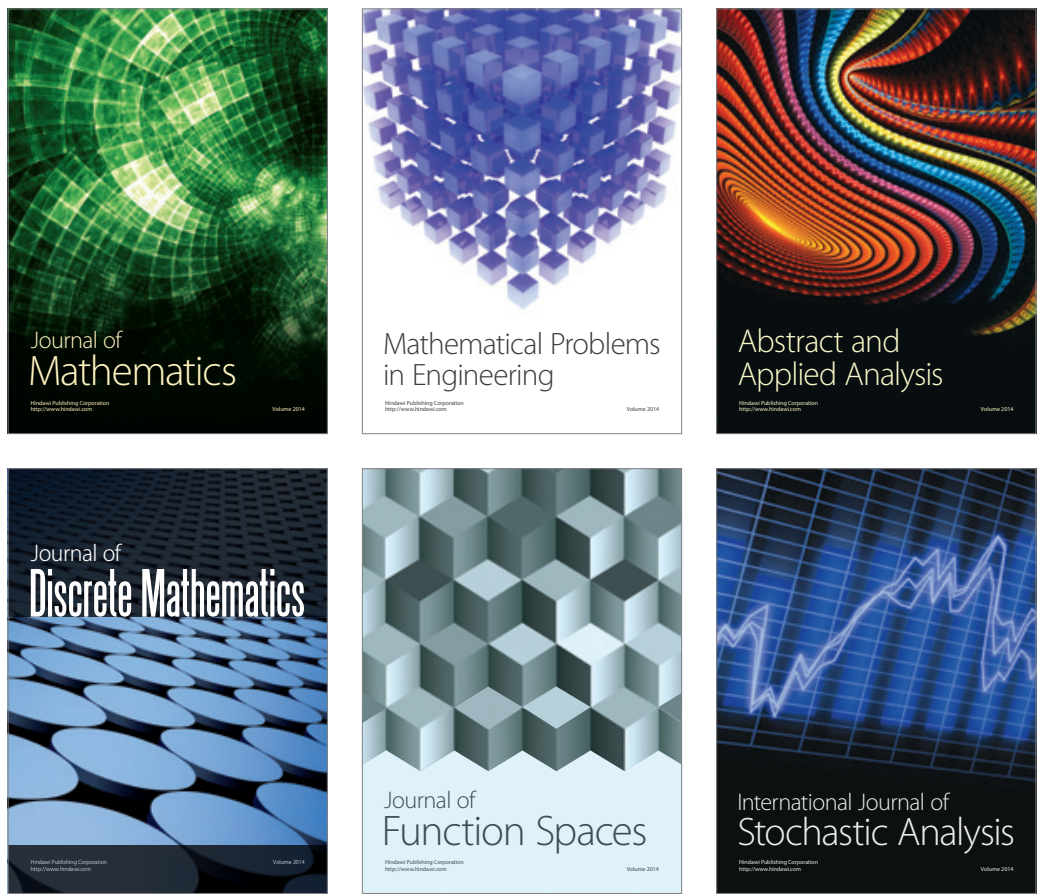

Journal of

Function Spaces

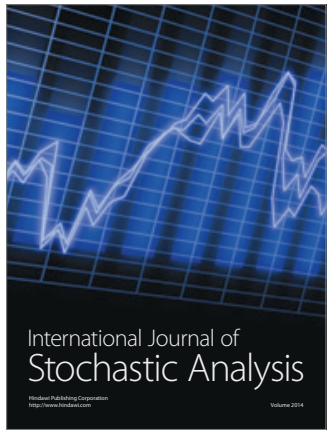

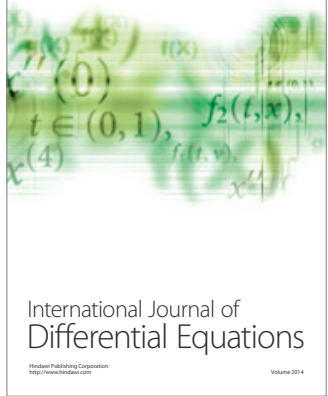
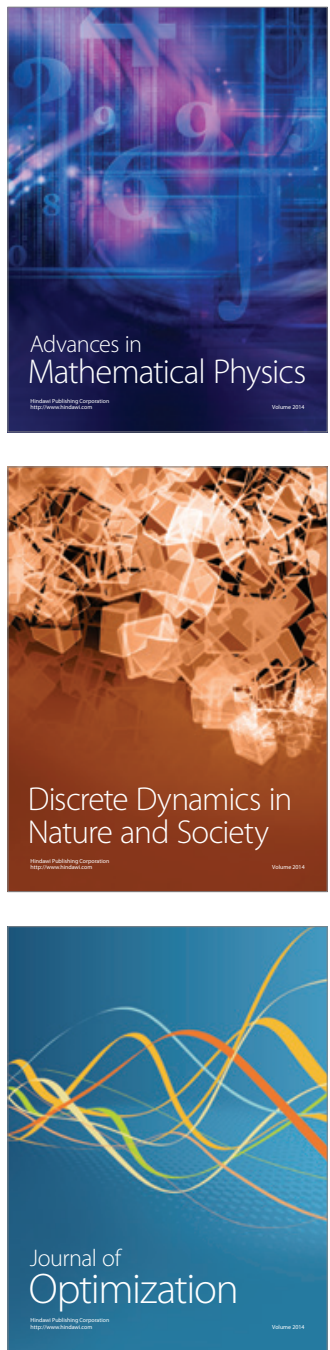